\title{
Development of a six-wheel drive vehicle: A comparative study on steering performance
}

\author{
Abd Rahim Shuib, Mohd Azwan Mohd Bakri, Mohd Khairul Fadzly Md Radzi \\ Malaysian Palm Oil Board (МРОВ), Malaysia
}

\begin{abstract}
The innovation for the recent agriculture tractors have been widely developed. These tractors are used to enhance the harvesting activities in way to lowering the labour cost. However, the current system of infield collection of oil palm fresh fruit bunches by using mini-tractor-trailer (MTT) has its limitation. This MTT have poor traction on soft ground such as coastal and peat areas which give the limiting factors that prohibit the usage of any mini-tractor. Thus, the aim of this project is to fabricate a functioning prototype vehicle consist of two-wheel steering (2WS) and four-wheel steering (4WS) in measuring its performance of tractive effort and steering radius for usage in palm plantation. The machine configuration consists of main chassis, compartment to carry oil palm bunches, a mechanism for loading purposes, operator cabin, and associated hydraulic system. The labouratory test of performance evaluation were conducted to the developed vehicle. The results show that under four-wheel drive (4WD) mode, the turning radius of the vehicle was found to be $42.9 \%$ lesser if the $4 \mathrm{WS}$ mode is engaged. For 6WD with $4 \mathrm{WS}$ active, the turning radius was $46 \%$ lesser while turning for $42.2 \%$ lesser compared to $2 \mathrm{WS}$. The slippage ranges are recorded between $8.5 \%$ to $22.5 \%$ where the slippage for the left wheel is negative as the left wheel rotates slower than the right wheel on the left turning of circular motion and vice versa. In addition, the vehicle design could be considered opti-
\end{abstract}

Correspondence: Abd Rahim Shuib, Malaysian Palm Oil Board (MPOB), No. 6, Persiaran Institusi, Bandar Baru Bangi, 43000 Kajang, Selangor, Malaysia.

E-mail: rahim@mpob.gov.my

Key words: Transporter; 6-wheel drive; 4-wheel steering; hydrostatic transmission; oil palm.

Acknowledgements: the authors would like to thank the DirectorGeneral and management in supporting the research works and permission to publish this paper.

See online Appendix for additional Table.

Received for publication: 28 December 2018.

Accepted for publication: 5 September 2019.

(C) Copyright: the Author(s), 2019

Licensee PAGEPress, Italy

Journal of Agricultural Engineering 2019; L:934

doi:10.4081/jae.2019.934

This article is distributed under the terms of the Creative Commons Attribution Noncommercial License (by-nc 4.0) which permits any noncommercial use, distribution, and reproduction in any medium, provided the original author(s) and source are credited. mum as the measured tractive effort of the vehicle was found to be $32 \%$ of the vehicle gross weight. This is within the recommended tractive effort, which is within a range of $30 \%$ to $36 \%$ of the suggested vehicle gross weight.

\section{Introduction}

Oil palm production in Malaysia currently occupies around 5.81 million hectares of which $2.71,1.55$ and 1.55 million ha in the Peninsular, Sabah and Sarawak, respectively (MPOB, 2017). The industry requires many workers for its operations ranging from planting to processing. Although the labour situation worsens over time, it is still manageable due to relatively relaxed foreign workers' policy. Some plantation operators find that there is no urgency to hurry for mechanisation. This is an investment that may soon backfire considering the fact that the labour situation is definitely not going to get better. Competition with a neighbouring country with larger land and labour reserves implies that dependency, on foreign workers, must be checked.

The current system of infield collection of oil palm fresh fruit bunches (FFB) uses trail type; particularly mini-tractor-trailer (MTT) system is well received by the private estate. From the observation made, the MTT has the limitation that its usage is confined to the firm ground, especially on flat and slightly undulating areas. Furthermore, poor traction on soft ground such as coastal and peat areas are the limiting factors that prohibit the usage of mini-tractor on these soil conditions. A single chassis transporter with off-road capability that surpasses the conventional fourwheel-drive tractor could be an alternative solution to the plantations. The vehicle also equipped with different attachment aid to improve traction while working under extremely wet area or steep terrain.

The proposed integrated collecting system would address issues of collecting and loading FFB to a container or transport vehicle for onward transmission to the mill with excellent mobility on various terrain conditions that are normally found in a typical oil palm plantation in Malaysia. Four-wheel steering on a single chassis trailers with three axles was studied by Yilmaz (1989). He found that due to non-linear movement, the rear axle wheels tend to slide when the trailer is making a turn. However, the sliding friction on the rear axle wheels can be minimised with contribution from its steering performance.

In ideal kinematically-correct steering, the axles of all the wheels during turning must be intercepted at one point. For three axles the turning centre is likely to occur at the middle axles, which are close to the centre of gravity. Middle and rear axles may slide during turning, but the middle axle may experience less resistance as it is nearer to the centre of gravity. The slides mostly will be encountered on the rear axles. This sliding motion has two major disadvantages: i) it increases the resistance against the movement; ii) sliding tyres wear out in a relatively short period of 
time (Yilmaz, 1998). This friction can be avoided by a mechanism that changes the slides into a turning action using a suitable angle during turning. This mechanical resistance as a result of friction can be avoided so that the life of tyres will be prolonged.

Thus, this paper presents the performance test of a six-wheel drive with 4-wheel steering vehicle to collect oil palm FBB in the palm plantation. Its focusing on the labouratory test of the prototype vehicle in terms of tractive performance i.e. tractive effort and steering radius. This transporter prototype vehicle has been upgraded where its compact design was emphasised with the intention of reliable and potential to operate on the peat and soft ground area.

\section{Materials and methods}

\section{Vehicle development}

The design of the 6WD with 4WS transporter with a moderate mass of up to $2700 \mathrm{~kg}$ including $1000 \mathrm{~kg}$ of payload and a high ground contact area would provide the transporter with a lower ground pressure of $112.8 \mathrm{kPa}$. Such a feature would give the transporter a lower sinkage and rolling resistance, thus providing the high tractive effort yielding higher travel speeds.

The transporter chassis was designed in such a way that all major components such as axle, engine, and hydraulic pump, hydraulic tank reservoir and fuel tank are placed at the appropriate point on chassis for easy maintenance. Figure 1 shows the transporter 3D-CAD drawing and its geometrical dimension. The $6 \mathrm{~mm}$ thick mild steel C-channel was considered for fabricating each of the transporter chassis to avoid the deflection of the vehicle frame for even double the total vehicle weight (ASAE Standard, 1996). With three axles, better load distribution can be achieved hence improving the traction of the transporter under demanding condition. The transporter has been designed where low ground pressure tyres can be fitted in place of conventional tyre that would enable the transporter to traverse on the soft ground area.

A $6 \mathrm{WD}$ with $4 \mathrm{WS}$ transporter having a single chassis configuration on three axles with six equal size tyres was successfully designed, developed and tested in the workshop and as well as in the field. The vehicle is powered by a 4-cylinder $45.3 \mathrm{hp} @ 2600$ rpm KUBOTA V2203-E single turbo water cooled diesel engine which was directly coupled to tandem units of EATON MD 72400 piston pumps and a unit of AIVIO model SP-20 auxiliary gear pump. Each of the EATON MD 72400 pumps was used to operate each high torque and low-speed CHAR LYNN series 6000 gear type hydraulic motors (Vickers, 1993). Apart from a standard front wheel steering, this transporter is also supplied with an additional steerable rear axle. This rear axle steering can be engaged and disengaged depending on the necessity. A more detailed technical specification of the transporter was given in Appendix 1.

\section{Transducers}

All-wheel torques are measured by a pair of specially made transducers that are mounted on each side of the wheel axles of the vehicle (Synder and Buck, 1990). The design of the transducer is based on an extension shaft that is securely mounted between the wheel axle flange and tire rim. An RBE-4A Kyowa slip ring and a specially made adapter are fitted to the end of extension shaft. Two sets of KFG-5-120-D16-11-LIM-2S Kyowa, 90 rosettes, $120 \pm 0.8$ $\mathrm{Ohm}, 2.1$ gauge factor strain gauges are bonded at $45^{\circ}$ shear planes

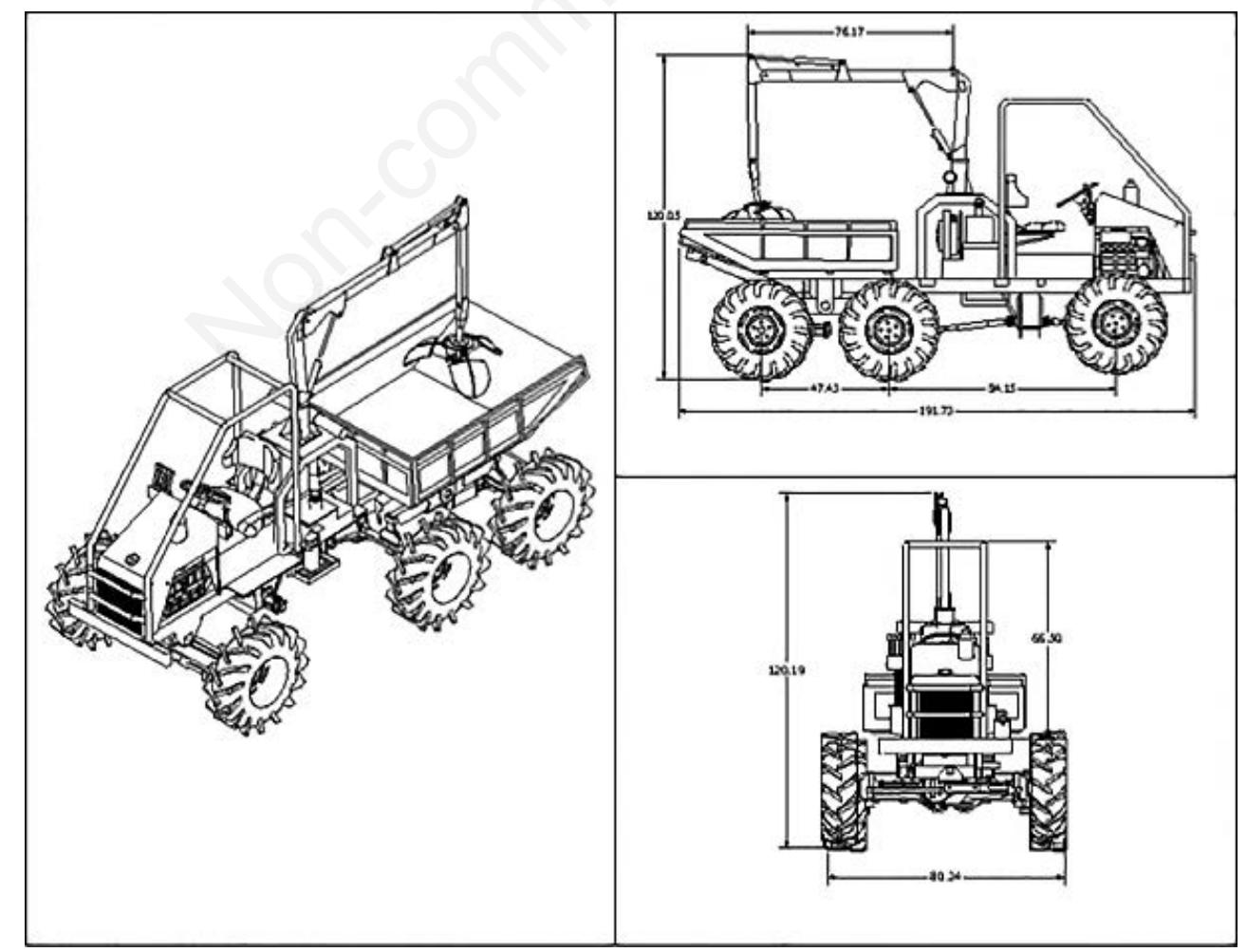

Figure 1. A CAD drawing and geometrical dimension of the transporter. 
on opposite sides of the extension shaft. The bonded strain gauges on the extension shaft are connected in a full bridge configuration. A $2.5 \mathrm{~mA}$ constant current excitation source is supplied from the data logger to each wheel torque transducers via its respective slip rings. Six L shaped steel conduits are mounted on each side of the transporter mudguards to carry the cables from the slip rings to the data logger, which is secured in a box shape metal behind the operator cab. To ensure the data logger will receive the minimum vibrations, the box is insulated by padding made of a rubber sheet to absorb the vibration. Each torque transducers is designed for a torque range of $0-32 \mathrm{kNm}$ and it has a sensitivity of 29.88 $\mu \mathrm{V} / \mathrm{V} / \mathrm{kNm}$.

\section{Calibration of transducers}

The static calibration tests of all the specially made transducers were done in four replications. Both ascending and descending load applications were considered to check the hysteresis effects on the transducers. The torque transducer was calibrated together by bolting the wheel hub with two to rigid pillars. The calibration solid torque arm was $75 \mathrm{~cm}$ in length with a five-hole round plate, and a rod bar to hang a known load at the other end. During the calibration process, the wheel is bolted to a rigid bar, and a chain is found to be more practical and easier to hang the dead weights. A series of dead weights, each of $20 \mathrm{~kg}$, was added at the end of the chain until it gave a maximum torque of $1060 \mathrm{Nm}$. Figure 2A shows the calibration set-up of sprocket torque transducer while Figure $2 \mathrm{~B}$ showing the completed calibrated wheel hub.

The torque transducer was made with bonding two sets of rosettes KFG-5-120-D16-11-L1M-2S Kyowa, 90 ${ }^{\circ}$ rosettes, 120 Ohm, 2.1 gauge factor strain gauges were bonded into the wheel hub surface, and a slip ring was mounted at the end of the shaft. The torque of the wheel hub was measured from the signal of the strain gauges and slip ring, which was recorded in the DEWE-2010 Data Acquisition System. An S4 Michigan Scientific slip ring is fitted to each end of the wheel hub to provide the strain gauges continuous cable transmission from the rotating wheel hub. The strain gauge circuitry from each side of the wheel hub was wired in series to a common DEWE-2010 Data Acquisition System at the vehicle instrumental panel. The digital meter could give the realtime measurements of the wheel hub torque in $\mathrm{Nm}$. Both transducers are designed for a torque range of 0 to $2136 \mathrm{Nm}$ and sensitivity of $0.00021 \mathrm{mV} / \mathrm{Nm}$.

\section{Velocity transducer}

The velocity transducer of the vehicle consists of with the DICKEY-John Radar II Velocity Sensor (RVSII) and the Omron E2E-X5-ME1 proximity sensor. The DICKEY-John Radar II Velocity Sensor (RVSII) that was used to measure the actual speed of the vehicle from their reflection (Kheiralla and Yahya, 2001). The unit consists of a transmitter/receiver assembly. It used the Doppler radar effect emitted from a $24.125 \mathrm{GHz}$ microwave to generate a frequency signal that is proportional to the speed of ground. This actual speed transducer is capable of measuring the vehicle travel speed in the range of 0.53 to $107 \mathrm{~km} / \mathrm{h}$. The sensor is not affected by dust, rain, and mechanical shock or vibration, and it is highly accurate.

The velocity radar sensor was connected with a 9-pin D-sub male connector. This connector was connected to a 9 pin D-sub female connector on the first DAQx-V analogue voltage input signal conditional module on the Dewe-2010 PC Instrument.

Omron E2E-X5ME1 proximity sensor with an instrumented 50 to teeth sprocket, was used to measure the theoretical speed of the vehicle. This sensor has a sensing distance of $5 \mathrm{~mm} \pm 10 \%$, setting distance in the range of 0 to $4 \mathrm{~mm}$, and a response frequency is $400 \mathrm{~Hz}$. The sprocket is fixed to the end of the custom-made wheel hub while the proximity inductive sensor is mounted by a specially made mounting bracket at the lower part of the vehicle frame as shown in Figure 3.
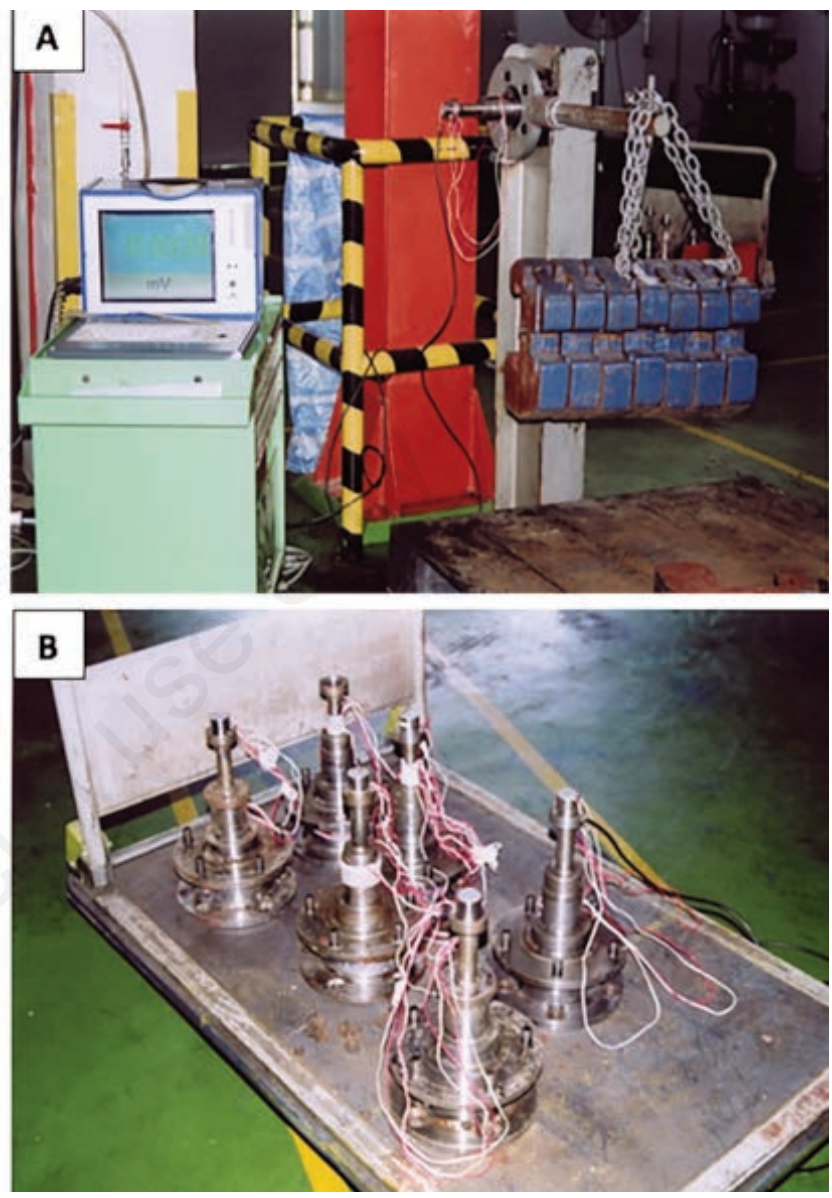

Figure 2. A) Torque transducer calibration; B) the completed six wheel hubs with transducer.

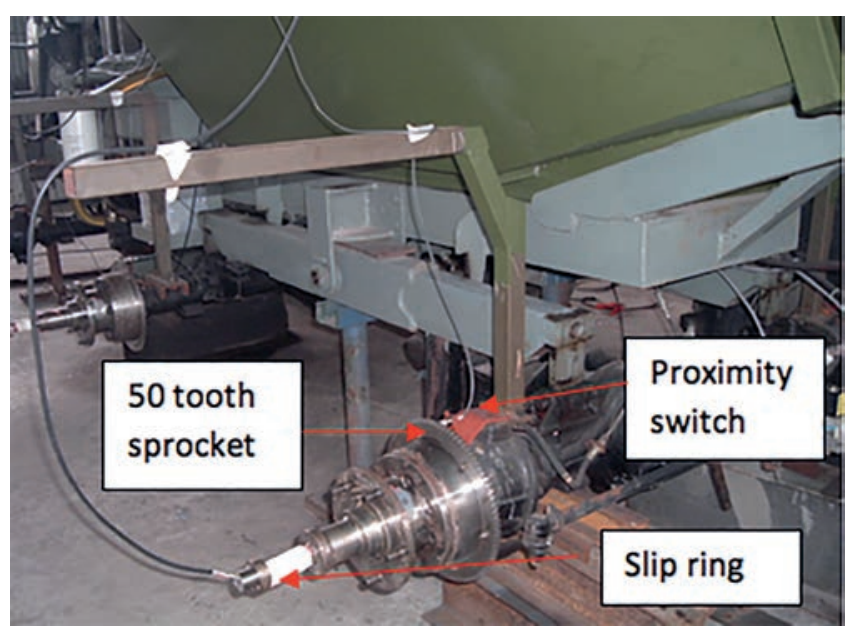

Figure 3. Arrangement of slip ring, transducer and proximity switch on vehicle axle hub. 


\section{Velocity transducer calibration}

This calibration value for this transducer was based on the work done by Ataur (2006). According to his calibration exercise, he has found that the standard error has an estimated value of 0.0091 . The R-square values of 0.9779 concluded that there were high relationships between the vehicle travelling speed and measured output voltage of the actual velocity transducers.

The linearity equation is expressed by:

$$
\mathrm{Vo}=0.2782(\mathrm{Va}) \text { with } \mathrm{R} 2=0.9788
$$

where Vo represents the output volt in V and Va is the applied travelling speed in $\mathrm{km} / \mathrm{hr}$. The obtained calibration equation was later programmed into the DEWE-2010 Data Acquisition System to give a direct readout of the vehicle's actual velocity in $\mathrm{km} / \mathrm{h}$.

\section{Results and discussion}

\section{Static load distribution}

Since the load is distributed on the axles, a simple study was conducted to measure its distribution on each axle. To carry out this study, a specially-designed load-cell-based weighing scale was constructed. Four units of load cells were mounted on each corner of the weighing platform. The weight of individual wheels was recorded, and the weight is totalled upper axle basis. The weight results of each wheel are recorded in Table 1.

\section{Centre of gravity location}

Centre of gravity of a vehicle is the most important design parameter for getting the high tractive performance. The vehicle under consideration with a total mass of $2400 \mathrm{~kg}$ including a total payload of $1000 \mathrm{~kg}$ is traversing on a zero slope terrain with a trav-
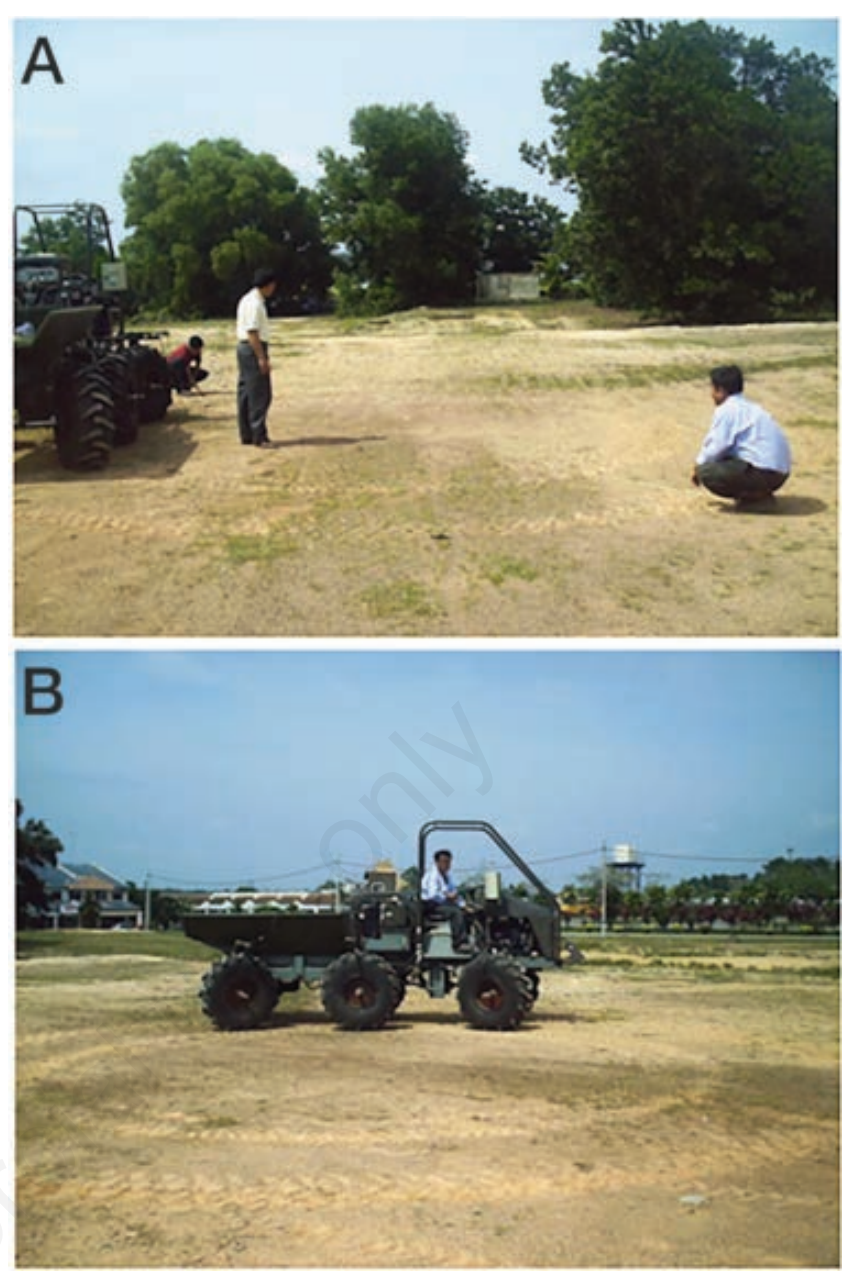

Figure 4. Measuring of turning radius of vehicle.

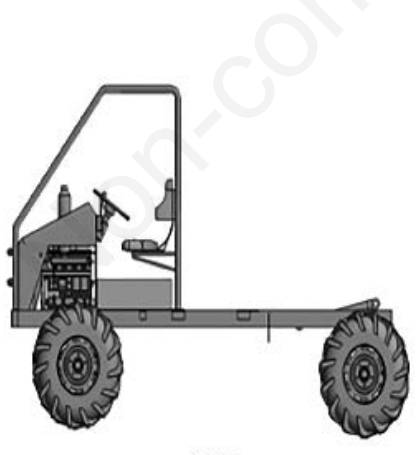

4WD

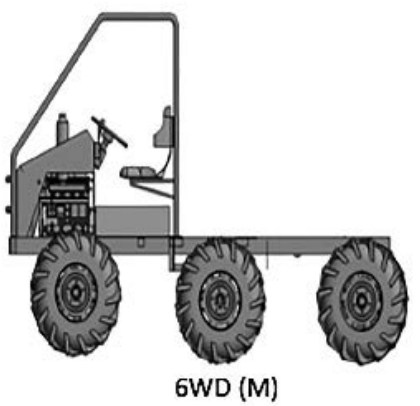

6WD (M)

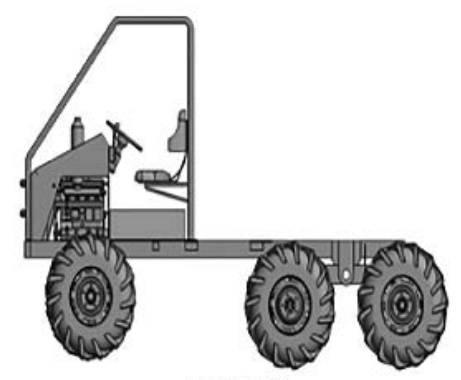

6WD (R)

Figure 5. Axle arrangement. 
elling speed of $15 \mathrm{~km} / \mathrm{h}$. The vehicle with centre of gravity located at $1256 \mathrm{~mm}$ rearward was measured from the front axle. From the comparison of the vehicle based on the location of centre of gravity, it is found that the tractive efficiency of the vehicle with centre of gravity located at $1226 \mathrm{~mm}$ rearward from the front axle. This will higher than the tractive efficiency of the vehicle with the centre of gravity located almost at the middle of the chassis.

If the chassis is seated on two axles, $49.3 \%$ of the load is distributed on the front axle, and the remaining $50.7 \%$ is distributed to the rear axle. Under three-axle arrangement with the middle axle at the centre, the front axle, middle axle and rear axle receives $47.6 \%$ and middle axle $26 \%$ and $26.4 \%$ respectively. Finally, under the three-axle arrangement with middle axle positioned close to the rear part of the vehicle, the load distribution was $45.2 \%$ for the front, $26.1 \%$ for middle and $28.7 \%$ for rear axle (Figure 4 ).

\section{Steering ability of the vehicle}

The test was conducted to measure the turning radius of the vehicle with $4 \mathrm{WS}$ and $2 \mathrm{WS}$ mode. The surface of the test area was selected based on its actual ground condition where this machine will be supposed to be operating, which is an oil palm plantation. The comparison of steering radius will actually depict the machine's ability to perform the task of collecting agricultural produce from the trees to the roadside. Under the 4WD mode, the turning radius of the vehicle was $42.9 \%$ lesser if the $4 \mathrm{WS}$ mode is engaged (Table 2). For 6WD with 4WS activated, the turning radius for the chassis with the middle axle at its centre, was $46.0 \%$ lesser while the turning for the transporter chassis with middle axle towards to the rear part was $42.2 \%$ lesser compare to $2 \mathrm{WS}$. However, the difference between $6 \mathrm{WD}(\mathrm{M})$ with $6 \mathrm{WD}(\mathrm{R})$ the was only $1.39 \%$ under $4 \mathrm{WS}$ steering mode (Figure 5).

\section{Steering behaviour of the vehicle}

The straight motion tests of the vehicle were performed in the site on firm round under different axle arrangements and steering modes. The machine was operated on 4WD with $2 \mathrm{WS}$ and 4WS. Under 6WD there was two-axle arrangement with the middle axle at the centre of the chassis and the middle axle to towards the rear axle. The abbreviation used in this exercise was 6WD (M) denoting the middle axle at the centre of the chassis and 6WD (R) referring to middle axle towards the rear axle. The travelling speed of the machine is kept between 6 to $12 \mathrm{~km}^{-1} \mathrm{~h}$ has to ensure the safety aspect as the machine always moves in a circle.
Before conducting the test to complete each of the replicates, the vehicle was made ready by installing the portable generator set and the DEWE 2010 on the vehicle. The instrumentation system was tested by executing the developed programme with DASY Lab 5.6 into the DEWE-2010 on the field. A preliminary run on the terrains was performed for ensuring the expected function of the instrumentation system of the vehicle.

Figure 6 show the vehicle slippage under different axle arrangements with similar tractive effort measuring method, which are 4WD with steering modes of $2 \mathrm{WS}$ and $4 \mathrm{WS}$. The measurement was carried both on both sides of steering, which was left and right. The recorded slippage range in between $8.5 \%$ to $22.5 \%$. There were positive and negative slippages under this exercise. If the machine makes a circle on the left turn, the slippage on the left wheel will be negative as the left wheel rotates slower than the right wheel. If the machine turns on right, the right axle will experience negative slippage (Brixius and Wismer, 1978). For example, Figure 6 shows the slippage results for the vehicle under 4WD2WS. Whenever the vehicle turned to the left side, the wheel hub 1 which was mounted on the front axle was recorded the speed of $7.91 \mathrm{~km} / \mathrm{h}$ while hub 2 on the right hand side wheel was $9.52 \mathrm{~km} / \mathrm{h}$, compared to the actual speed of the vehicle which was $8.71 \mathrm{~km} / \mathrm{h}$. Beside, the opposite slippage results was obtained when the vehicle was turned to right side with the speed of hub 1 was $8.56 \mathrm{~km} / \mathrm{h}$ and hub 2 was $6.05 \mathrm{~km} / \mathrm{h}$ compared to actual speed which was 7.31 $\mathrm{km} / \mathrm{h}$.

Figure 7 show the vehicle tractive effort which travelling under $4 \mathrm{WD}$ and $2 \mathrm{WS}$ steering mode. The average tractive effort recorded was $6.66 \mathrm{kN}$ on left steering and $6.82 \mathrm{kN}$ while travelling on making right-hand turn.

\section{Conclusions}

A mechanised system for infield collection and transportation of fresh oil palm fruit bunches had been successfully designed, developed and tested in the labouratory (workshop) as well as in the field. Tractive performance of the vehicle was evaluated by testing the vehicle on two modes of steering $2 \mathrm{WS}$ and $4 \mathrm{WS}$ as well as different axle arrangements $4 \mathrm{WD}, 6 \mathrm{WD}$ with middle axle substantially at the centre of the chassis, and $6 \mathrm{WD}$ with middle axle towards the rear axle. Under 4WD mode, the turning radius of the

Table 1. Mass of individual wheel.

\begin{tabular}{|c|c|c|c|c|c|c|c|}
\hline \multirow{2}{*}{ Axle arrangement } & \multicolumn{2}{|c|}{ Front axle (kg) } & \multicolumn{2}{|c|}{ Middle axle $2(\mathrm{~kg})$} & \multicolumn{2}{|c|}{ Rear axle 3 (kg) } & \multirow[t]{2}{*}{ Total (kg) } \\
\hline & Left & Right & Left & Right & Left & Right & \\
\hline 4WD & 545 & 551 & - & - & 560 & 565 & 2221 \\
\hline 6WD (M) & 549 & 566 & 297 & 312 & 308 & 311 & 2343 \\
\hline $6 \mathrm{WD}(\mathrm{R})$ & 524 & 547 & 290 & 326 & 338 & 340 & 2365 \\
\hline
\end{tabular}

Table 2. Steering radius of vehicle on different axle arrangement.

\begin{tabular}{lllcc} 
Mode of steering & & 6WD (M) & 6WD (R) \\
\multirow{2}{*}{ 2WS } & Left turn (m) & 8.41 & 8.69 & 8.71 \\
& Right turn (m) & 7.27 & 7.57 & 7.59 \\
\multirow{2}{*}{ WWS } & Left turn (m) & 4.81 & 4.96 & 5.03 \\
& Right turn (m) & 4.44 & 4.49 & 4.57 \\
\hline
\end{tabular}



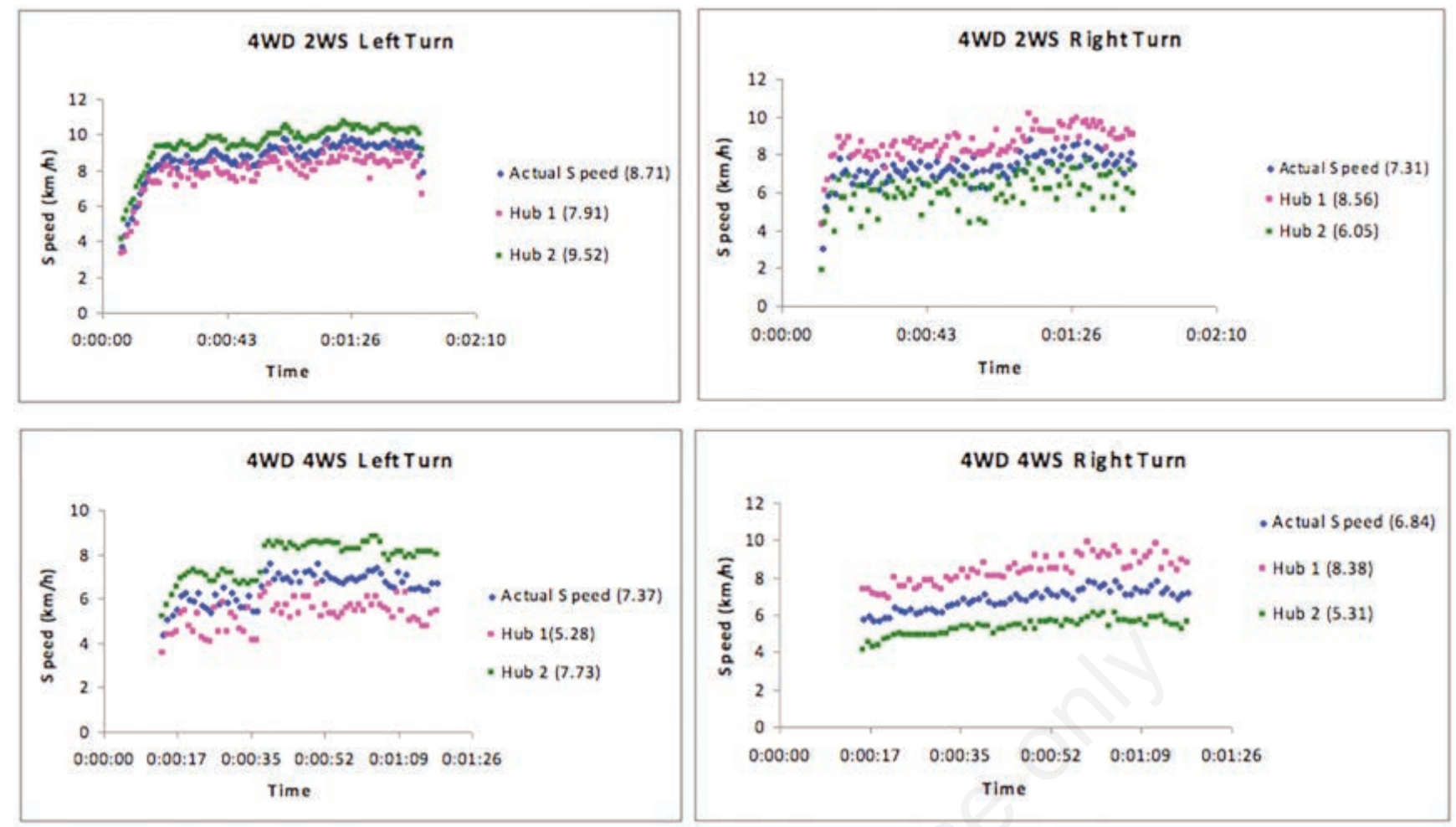

Figure 6. Slippage of the vehicle under $4 \mathrm{WD}$ with $2 \mathrm{WS}$ and $4 \mathrm{WS}$ making left or right turn.
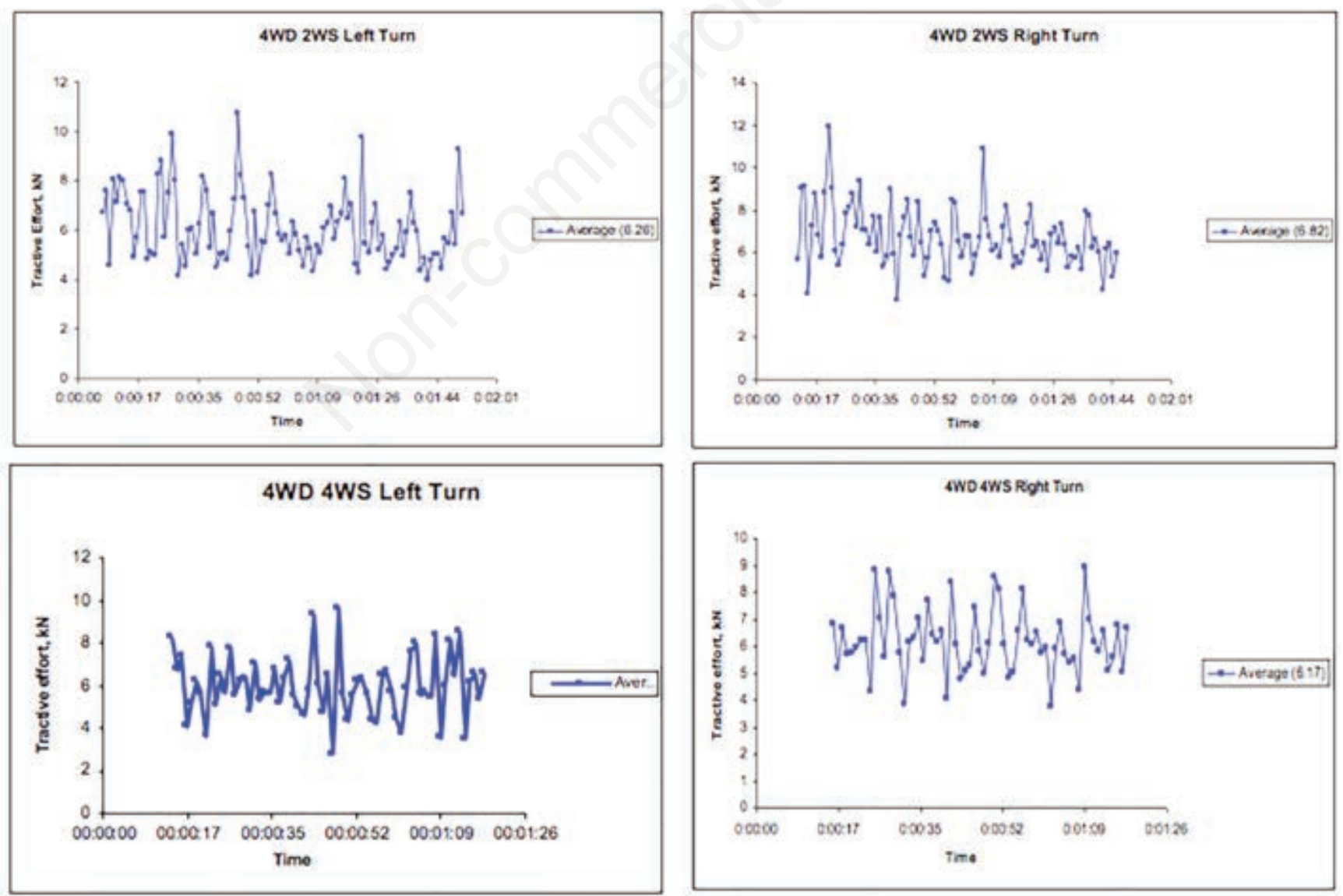

Figure 7. Vehicle tractive effort with 4WD and 2WS mode making left and right turn. 
vehicle was $42.9 \%$ lesser if the 4WS mode is engaged. For 6WD and 4WS with activated, with the middle at the centre of the chassis, the turning radius was $46 \%$ lesser while with middle axle towards to the rear part of the transporter chassis the turning radius was $42.2 \%$ lesser compare to $2 \mathrm{WS}$. The recorded slippage ranged in between $8.5 \%$ to $22.5 \%$. The vehicle design could be considered optimum as the measured tractive effort of the vehicle was found to be $32 \%$ of the vehicle gross weight. This is within the recommended tractive effort, which is within a range of $30 \%$ to $36 \%$ of the vehicle gross weight suggested by Wong (2001). Based on the current prototype, the present chassis is over sizing and should be restudied to optimise the power requirement. The tendency of over sizing during the prototyping stage is to ensure the unit work first before further refinement could be done to optimise the design parameter.

\section{References}

ASAE Standards. 1996. Standards Engineering Practices Data: ASAE S430. Agricultural Equipment Tyre Loading and
Inflation Pressures. 43 ${ }^{\text {rd }}$ Edition. ASAE, St. Joseph, MI, USA. Available from: https://elibrary.asabe.org/standards.asp

Brixius W.W., Wismer R.D. 1978. Role of slip in traction. Pap. Am. Soc. Agric. Eng. Available from: https://www.asabe.org

Kheiralla A.F., Yahya A. 2001. A tractor data acquisition system for power and energy demand monitoring of agricultural field operations. J. Sci. Technol. 9:51-67.

MPOB (Malaysian Palm Oil Board). 2017. Pocketbook of oil palm statistics 2017. Available from: http://intranet.mpob.gov.my

Synder K.A., Buck N.L. 1990. Axle instrumentation for tractive performance parameter measurement. Trans. ASAE. 33:290-7.

Vickers I. 1993. Vickers industrial hydraulics manual. 3rd ed. https://www.eaton.com

Yilmaz M. 1989. Steering of rear axle wheels in three-axle trailers. AMA (Agric. Mech. Asia). 20:66-8.

Yilmaz M. 1998. Automatic backward motion steering of tractor with two-axle trailer combination. Agric. Mech. Asia Africa Lat. Am. 29:47-50.

Wong J.Y. 2001. Theory of ground vehicle. 3rd ed. Wiley, London, UK. 